\title{
The shaping effect of the Belt and Road Initiative on China's international oil and gas cooperation strategy ${ }^{\star}$
}

\author{
Qian Liu, Xiaoguang Wang \\ China University of Petroleum (Beijing) \\ 18, Fuxue Road, Changping District, Beijing (102249), China
}

For citation: Qian Liu, Xiaoguang Wang. The shaping effect of the Belt and Road Initiative on China's international oil and gas cooperation strategy. Vestnik of Saint Petersburg University. International Relations, 2020, vol. 13, issue 1, pp. 20-32. https://doi.org/10.21638/spbu06.2020.102

The Belt and Road Initiative (BRI) was launched as a leitmotif of China's economic diplomacy in 2013 after Xi Jinping assumed power. Inevitably, China's behaviors in international oil and gas cooperation have been influenced by the BRI in terms of policy purpose, cooperation model, business organization, and even energy security strategy. Under the BRI, China's originally primary purpose of natural resource access in oil and gas cooperation has shifted to a business-based strategy. Meanwhile, China has constructed oil and gas pipelines as common interest-based interconnections of infrastructures, instead of getting involved in geopolitical games. In the process, China and large national companies play as partners and coordinators more often even as their traditional roles are operators and majority shareholders. Coupled with the transition of purpose, the cooperation model also changes to an industrial chain-based model. China's overseas oil and gas cooperation transitioned from an "upstreamdownstream integration" model to a "module plug-in" model, which flexibly includes natural resources, trade, transportation, refining and engineering services to prompt the "going-out" of China's technology, equipment, and industrial capacity. In the organization of international oil and gas cooperation, coordination among the majors of Chinese national oil companies, and between national oil companies and other actors has become independent. The Yamal project provides an empirical case that displays China's transition in international oil and gas cooperation under the BRI in this article.

Keywords: China, BRI, oil and gas, international cooperation.

\section{Introduction}

Several factors have contributed to the People's Republic of China's soaring demand for energy in past decades, such as economic growth, a higher living standard, and the country's integration into the global economic system. However, the domestic production of energy is far lower than what China needs, especially in oil and gas. In recent years under Xi Jinping, China's environmental policy has also challenged the use of coal that still accounts for the greatest proportion (about $60 \%$ ) of Chinese primary energy consumption; the environment policy of cutting coal consumption has additionally produced a request for a greater degree of security for the oil and gas supply. After 1993, when China became a net importer of crude oil, Chinese national oil companies (CNOCs) launched

\footnotetext{
* This research is funded by the Ministry of Education of China (15YJCGJW005).

(c) Санкт-Петербургский государственный университет, 2020
} 
their overseas campaigns to seek international cooperation on oil and gas, becoming the earliest Chinese commercial entities to engage in the international business arena.

By 2013, the year President Xi Jinping announced the Belt and Road Initiative (BRI), CNOCs have completed their 20-year "going-out" strategy. In the process, CNOCs accumulated substantial experience and skills in the international oil and gas arena, particularly concerning energy resource investment, exploration and development, engineering service, construction, and equipment; moreover, they formed their own international cooperation models, such as the "upstream-downstream integration" (UDI) and "oil-backed loans plus infrastructure". At the same time, CNOCs in global competition also acknowledged major drawbacks in their business operation, such as their feeble technical competitiveness against international oil companies and financial losses owing both to failed projects and asset mismanagement. The genesis of the BRI ensures that China's overseas oil and gas cooperation must inevitably merge with the mega geo-economic strategy during of Xi's presidency. Nevertheless, international oil and gas cooperation and CNOCs' overseas operations are influenced both politically and economically by the BRI. The shaping effect of the BRI upon China's international oil and gas cooperation is the topic of this article. After first introducing the foundation of international oil and gas cooperation before the BRI, it then analyzes the fundamental principle in international economic cooperation of the BRI. Next, the article will detail and examine how these principles are applied to the oil and gas business, followed by a case study of the role played by China and CNOCs' in the Yamal Liquefied Natural Gas (LNG) Consortium (hitherto Yamal project), as empirical evidence. Finally, the shaping effect of the BRI upon China's international oil and gas cooperation will be discussed.

\section{The foundation of international oil and gas cooperation in the BRI}

Xi Jinping introduced the concept of the BRI in 2013 in Kazakhstan and Indonesia. The BRI includes two major branches. The first is the Economic Belt of the Silk Road that connects China with Russia, Central Asia, the Middle East, and Europe. The second is the $21^{\text {st }}$ Century Maritime Silk Road that traverses Southeast Asia and links China to the Indian Ocean, the Red Sea, and the Mediterranean. It is easy to notice that the two economic corridors cover the most important energy producers and energy transportation routes worldwide.

In the framework of the BRI, energy is a priority issue in China's development and state security strategies. According to Xi Jinping, and energy supply security should be built on both domestic production, in addition to international cooperation [1]. However, the fact is, in past 25 years, China has been increasingly dependent on external energy supply. At the end of the second decade of $21^{\text {st }}$ century, more than $70 \%$ of the crude oil and $45 \%$ of the natural gas China consumes come from overseas. Such a high external energy dependency is always evaluated as a potential risk to national economic development and social stability. By far, several key suppliers of oil and gas, including Russia, Central Asia, and the Middle East, are in the key regions of BRI planning. Kazakhstan, where $\mathrm{Xi}$ Jinping announced the BRI to the world, was one of China's earliest energy partners. Therefore, energy cooperation is relevant for the BRI.

The foundation of energy cooperation in BRI is the rich energy resource in BRI regions. The crude oil reserves in BRI countries reach 13.15 billion tons, accounting 
for $55 \%$ of the global share; the natural gas reserves reach 142 trillion cubic meters, accounting for $76 \%$ of the global share [2]. The oil and gas industries also play a key role in the energy resource countries in BRI regions. As China is one of the largest and most crucial energy markets worldwide with a great potential for increased energy demand, the reciprocal relation in energy cooperation between China and the BRI regions should be solid.

Before the BRI, CNOCs and a number of Chinese private energy companies engaged in cooperation within the BRI regions. For example, China National Petroleum Corporation (CNPC), perhaps the bellwether of the CNOCs, was engaged in more than 50 projects in Russia, Central Asia, Middle East, and Southeast Asia in 2014 and realizing an annual equity output equal to 50 million tons of crude oil [3, p. 29]. Sinopec Group has more than 20 projects in BRI regions with combined equity output of 25 million tons [4, p. 31]. The smaller China National Offshore Oil Company (CNOOC) also had eight projects in the Middle East and Southeast Asia. Due to the effort of both the Chinese companies and their cooperation partners, there were until 2014 several mega energy infrastructures connecting China and neighboring countries in operation, notably the China-Central Asia Natural Gas Pipeline, the China-Kazakhstan Oil Pipeline, the China-Russia Oil Pipeline, and the China-Myanmar Oil and Gas Pipeline, among others, forming the annual import capacity of 35 million tons of crude oil and 67 billion cubic meters of natural gas. Such international oil and gas cooperation initiatives largely improved China's energy supply, boosted the political trust between China and its partners, and critically laid down a solid foundation for the BRI for further development in other social, economic and developmental aspects.

\section{The principles of BRI to international economic cooperation}

One of the most important characteristics of the BRI is its emphasis upon "connectivity" in international economic cooperation. In the speech in Astana, Xi highlighted five key fields for connectivity within the BRI framework, including policy, transportation, trade, finance, and people-to-people communication [5]. The traditional implication of "connectivity" always refers to one instrumental policy for one specific purpose, such as building an oil pipeline to access oil resources. However, under the BRI framework, the multi-level and multi-themes "connectivity" become the strategic purpose, rather than simple instruments, to some degree. Xi publicly said that "China should not be the solo actor in the BRI... and what China wants is not its own backyard but a public garden" [6]. In comparison, as a systematic strategy, BRI upholds the idea that different economic factors should serve and support each other in the multi-themes connectivity. Finally, the BRI is also placed with the purpose of platform for economic globalization and common prosperity. This is done with an eye on contributing to the grand concept of building "Community of Shared Future for Mankind" [7].

Another, perhaps unintentional, consequence of the BRI's emphasis upon "connectivity" is that China has begun to pay more attention to economic cooperation with its neighboring countries. Physical connectivity and economic policy coordination is easier to build between neighboring countries. Regarding the energy issue, cooperation with countries sharing a border with China can escape the potential risks from long distant transportation and transit counties. Such countries naturally have a higher degree of en- 
ergy security implications for China, especially compared with countries in Africa and Latin America countries [8].

Another important principle of the BRI is the decisive role of the market mechanism in international economic cooperation. The State Council's National Development of Reform Commission (NDRC), the highest economic planning organ of China, issued a guideline that the BRI "will abide by market rules and international norms, give play to the decisive role of the market in resource allocation and the primary role of enterprises, and let the governments perform their due functions" [9]. China, in the process of publicizing the BRI to external world, attempted to select careful wording that would avoid creating the impression by other countries that the BRI was a geopolitically driven project or international development assistance at China’s economic expense.

\section{The transition of China's international oil and gas cooperation under the BRI}

Because of the guidelines stipulated by the BRI, CNOCs and perhaps the whole Chinese oil industry have to adapt to the new political climate. Compared with the past 20 years "going-out", the major transition is reflected in four dimensions: the purpose, the cooperation model, the business organization, and, finally, the energy security strategy.

\section{The changing purpose in international oil and gas cooperation}

The natural resource was the core purpose in China's international oil and gas cooperation. The fundamental principle of China's participation in international oil and gas cooperation was declared as "two markets, two kinds of resources". This referred to domestic and international markets of crude oil and natural gas; the internal logic of this principle was to use international resources to cover the domestic gap between production and consumption. Guided by this principle over the past 20 years, CNOCs strove to be the "operator" in international oil and gas cooperation. In the process, CNOCs could easily access to the upstream resources in other countries. Meanwhile, employing flexible models such as "Upstream-Downstream-Integration (UDI)" [10] and "Oil-backed Loans Plus Infrastructure" [11], CNOCs can generate the energy production capacity in a short timeframe in tough conditions overseas and transport oil and gas produced overseas to international and Chinese markets, with relatively low cost. Such cooperation effectively reduces the geopolitical risks for China, through several key oil and gas import channels.

Under natural resource-centered approaches, China has successfully maintained upstream cooperation in several countries since the 1990s, especially in countries such as Kazakhstan and Turkmenistan in Central Asia; in Sudan, Chad, Niger, and Angola in Africa; and Iraq in Middle East. With the development of these kinds of cooperation, several key oil and gas import channels connecting China with Russia, Central Asia, and Myanmar were completed, as introduced above, in addition to the oil and gas imported from China's eastern costal region. These endeavors effectively guaranteed the oil and gas supply security for China.

However, with the development of international and domestic oil and gas markets, the old resource-centered strategies have consistently been challenged by various factors. Initially, due to increasing investment volume and operation difficulty, CNOCs are not 
easy to control any single project or to serve as operator of a project. Meanwhile, with the experience of the international oil and gas arena and the energy resources controlled, the coordination capacity of CNOCs has been substantially enhanced. Under these conditions, CNOCs are more able and willing to operate transportation of crude oil and gas on a global scale, but not to ship all overseas productions back to China. With this background, in responses to the BRI, China's purpose of international oil and gas is also changed.

Initially, CNOCs do not regard being "operator" or being the biggest shareholder as the primary demand in international oil and gas cooperation. In turn, CNOCs are inclined to cooperate with other international/national oil companies to diversify investments and mitigate risks. Typical cases include the Kashagan project in Kazakhstan and the Yamal project in Russia's Arctic region. In the transition, the prioritized target incrementally changed from to access to energy resources to the economic benefit and the networks with international partners.

Meanwhile, in addition to the purpose to natural resource, the construction of oil and gas pipelines no longer shoulder the responsibility to transport oil and gas to China alone; rather, this would be accomplished via an economic network to realize regional connectivity and prosperity. For example, the first line of the China-Central Asia Natural Gas Pipeline (Line-A) was completed in 2009, with a focus on transportation of gas in Central Asia to China. With the development of the infrastructure, the third pipeline (Line-C) and the Beineu-Bozoy-Shymkent Pipeline were completed in 2015, also transported natural gas to the Southern part of Kazakhstan, making local use of natural gas possible. Based on the Line-C and the Beineu-Bozoy-Shymkent Pipeline, Kazakhstan is constructing the Salyarka Pipeline to supply natural gas to the capital city Nur-Sultan. The proposed Line-D will even further connect two Central Asian countries with no rich oil and gas resources, namely Tajikistan and Kyrgyzstan, to the China-Central Asia Natural Gas Pipeline. This move cannot be explained by traditional pipeline construction logic for China. Rather, this move is motivated by the BRI principle of serving the broader region rather than China alone.

\section{Industrial chain-based cooperation}

One of the most critical guidelines of the BRI is the international cooperation on production capacity [12]. The construction and engineering services in the oil industries in BRI regions could reach to US\$ 200 billion and 50 billion, respectively [13]. When CNOCs no longer regard access to energy resources as the ultimate target, the industrial based cooperation becomes a new focus. This has accelerated under the BRI.

A very successful approach by CNOCs in international oil and gas cooperation is the so-called UDI model. Under the UDI model, CNOCs simultaneously operate upstream exploration and development and provide services in drilling, oilfield construction, design, and construction of pipelines, refineries, and equipment. The UDI model effectively coordinates the different industrial sectors in oil industry, reducing the cost and time, increasing the profitability of CNOCs' international cooperation. In past decade, this UDI model even constructs the oil industry in some start-up resource countries that did not have oil industry and import crude oil, showing both economic and political benefits [14].

The UDI model also faces increasing difficulties in recent years, with the expansion of UDI model. Initially, CNOCs compete for internal interests within UDI projects; such 
competition exists among actors of different parts in the same industrial chain over a single project or among actors of the same business in different projects. In this scenario, the advantages of UDI model must be compromised. Meanwhile, with the development of oil and gas cooperation, the demand of engineering and construction know-hows are increasingly specialized. CNOCs are incapable of handling the whole industrial chain in highly various UDI projects, especially in some super-size UDI projects or high-tech driven UDI projects. Therefore, there is an urgent need for cooperation among different specialized companies in resource, technology, equipment, construction, and business to revise the current UDI model. Therefore, under the BRI, China's UDI model is quickly shifting to one of industrial chain-based cooperation. The emphasis upon industrial chain-based cooperation is no longer to take external natural resources into China but to export China's capacities in technology, equipment, and construction out to international cooperation partners.

The CNPC's role in Yamal exemplifies the industrial chain-based cooperation. CNPC only holds a $20 \%$ share in the project; also the original proposed market of Yamal project was Europe. CNPC can control neither the decision-making nor natural resource throughout the project. However, CNPC, as chief coordinator on the Chinese side, actively introduces Chinese companies in engineering, construction, equipment, ship-building and financial service into the Yamal project. In the process, at least 45 Chinese companies provide more than 100 types of products or services to the Yamal project, promoting the international presence and technological development of Chinese companies [15].

\section{The transformation of business organization}

In this article, business organization refers to the relations among different Chinese actors in the international oil and gas cooperation. On the Chinese side, Chinese central government and CNOCs are the most direct and dominant actors; moreover, their behaviors are intimately connected with China's energy security and economic interests. Beside CNOCs, various government organs, think-tanks, financial institutions and other supporting units in China's international oil and gas cooperation and any strategic on the issue must lead to a change in business organization.

In the past 2 decades, international oil and gas cooperation for China featured a "topdown" organization. As such, cooperation was always initially led by the central state government of China through inter-government agreements with the national governments of partners; thereafter, national oil companies (always only one) worked from beginning to end as the state's proxy to complete the agreement and finally realize the national goal (often energy security). Beside CNOCs, the policy planners and monitors are NDRC, the State Administration of Energy, and the State Assets Supervisory Administration Commission. Various think tanks such as the Chinese Academy of Engineering provided intellectual support, and financial institutions provided financial assistance. In the process, every actor played its own due function, such as research, labor force, financial assistance, or material support to make sure the national goal can be realized. This mode is heavily influenced by the state-driven mobilization approach in developing Chinese domestic oil and gas fields [16].

Under the BRI, companies can have a say in decision-making based on their own business interest, at least partially, and definitely are also responsible for economic performance 
of their decisions. By contrast to the pre-BRI mode, inter-government engagements under the BRI provide political foundation and trust, rather than an order for an explicit target. In this sense, CNOCs in the international arena are more like the "club team" rather than the "national team". Like CNOCs, different actors can also have their own purposes and make decisions about participating in international oil and gas cooperation based on their own perspectives of the commercial opportunities. In this scenario, the BRI provides a common macro context for policy making. Because of the BRI, above actors who have different perspectives and interests can discuss the issue in a more narrowly defined dimension and set some more common targets for international cooperation. This move makes the whole process of decision-making from different actors more scientific and coordinative but certainly less organized like the campaign than 20 years ago.

Under the reformed business organization, the relations among state organs, CNOCs, financial institutions, and even other supportive sectors are more diversified; moreover, different actors are more independent in the process. Through their participation in the Russian Arctic liquefied natural gas (LNG)-2 projects, CNPC and CNOOC equally acquired their own $10 \%$ share in the project. At the same time, CNPC and CNOCC jointly developed cooperation with other international oil companies such as Shell Oil and Total. In addition, Chinese financial institutions and investment funds also play their due roles in international oil and gas cooperation under the banner of the BRI. The Silk Road Fund acquired a 9.9\% share of the Yamal project, and the Asian Infrastructure Investment Bank (AIIB) provided the loans to fund TANAP, the natural gas pipeline connecting Azerbaijan and Europe. In these projects and others, the BRI has provided mega project-centered business organization under which different actors in the process are driven by respective commercial interests and business competitiveness for their own sake. Under the transformation of business organization, CNOCs and their subsidiary companies are prudent in entering the fields in which they do not have a prior advantage; instead, they are more inclined to cooperate with international partners to hedge the risks of investment and operation.

\section{The evolution of energy security strategy}

It may be confidently asserted that the BRI does not ignore the issue of energy security at all; however, the Chinese perception of energy security has evolved within the framework of the BRI. From the state to CNOCs, China gradually accepts a more market mechanism-based approach to realize energy security. In practice, the approach to realization of a secure oil and gas supply for China has been shifting from bilateral cooperation to depending on the open international oil and gas market. In this climate, Chinese domestic marketization reform of oil and gas industry have also accelerated.

Since the 1990s, China and CNOCs wish to secure oil and gas supply through bilateral cooperation with resource countries. The effort largely consolidates the oil and gas supply capacity and supports the Chinese economic development. However, this approach also faces challenges. Initially, within a high oil price business circle, resource countries are unwilling to engage in bilateral cooperation as international market favors resource countries, this is spelled out in the failed proposal of building the Angarsk-Daqing Oil Pipeline. By contrast, in the low oil price business circle, bilateral cooperation demonstrates the problem of rigidity within China, as oil producers in bilateral cooperation wish to make large profits by selling more oil than China cannot consume. Under the market principle of the BRI, bilateral 
cooperation has gradually merged into international market mechanism. CNOCs select to sell what they produce in faraway regions directly to the international market. Under BRI, cooperation partners are now the world's biggest oil producers, like Saudi Arabia and Russia, when China buying American shale oil is also on the agenda.

In the domestic arena, the three major CNOCs no longer hold a monopoly over China's international oil and gas business cling the monopoly to running international oil and gas business, and so-called "teapot" refineries even can form a strong power to influence Chinese domestic market of oil products [17]. In addition, the competition within the domestic market is also heated among the three major CNOCs, as they have different import channels for oil and gas. Finally, in response to the international norm of splitting between energy producers and transporters, China has established a state-owned pipeline line company based on the domestic oil and gas pipelines assets of the major CNOCs [18].

\section{Case study: China and the Yamal LNG project}

The Yamal project is a large-scale LNG production project run by the Russian energy company Novatek in the Yamal Peninsula of the Arctic region. The US\$27 billion project is based on the resources in the South Tambey Field and currently includes three production lines and a designated annual production capacity of up to 16.5 million tons of LNG [19]. Yamal is the first energy project China has engaged in within the Russian Arctic region, and the project enabled CNPC for the first time has come to hold a share of Russian upstream hydrocarbon assets. In addition, the Yamal project is equipped with a special political attribute as it reflects the zeitgeist of the BRI and the jointly launched Sino-Russian "Polar Silk Road" strategy [20].

Sino-Russian cooperation on the Yamal project was first negotiated in early 2015 between then-Chinese Vice Premier Wang Qishan and then-Russian Vice Premier Arkady Dvorkovich. After comfortable time at the highest political level, energy companies in China and in Russia began to engage in the project. CNPC and Novatek signed the agreement in June 2013, and the ceremony was witnessed by then-Chinese Vice Premier Zhang Gaoli and Russian President Vladimir Putin. In following months, CNPC purchased a $20 \%$ share of the Yamal project. The first production line was completed 47 months later and the whole project was completed seven months early. This construction process was highly efficient given the harsh natural conditions of Arctic region and the international sanctions against Russia [21].

\section{The transition of purpose: Beyond natural resource}

In Sino-Russian energy cooperation before Yamal, CNPC and other Chinese oil companies became aware of the nationalistic natural resource policy of Russia (limit for foreign shareholding and strict investment review) and dominant role of Russian energy companies (majority holder and operator of project must be Russian). Therefore, they hesitated to take part in the Yamal project, particularly as several failed or cancelled proposals had existed before Yamal, including the cases of attempting by Chinese companies to purchase Slavneft and the Angarsk-Daqing oil pipeline. In terms of the background of the Yamal project, the initial evaluation from CNPC was not optimistic 
owing to the project's location in a high-risk region and its uncertain economic efficiency. In addition, CNPC needs to invest a great deal of money in the Yamal project but its share in the project is too small to influence decision-making. These points pose difficulties CNPC faces in investing in the Yamal project, as it does not meet the traditional principles of Chinese oil and gas investment introduced above.

However, CNPC also noticed several advantages to the Yamal project. Initially, the shareholders had alternative resources: Novatek is no doubt a rising star in the Russian natural gas industry [22], and the LNG business is highly significant for Novathk [23]. In addition, other shareholders in the project have their own competitiveness. For example, shareholder Gennady Timchenko has a close relationship with the Russian government; meanwhile, French oil and gas giant Total has advanced technological and management skills. Meanwhile, the Russian government around 2013 issued a series of policies favorable to the project, including liberalizing the LNG export [24] and rendering a Yamal project tax-cut. In addition, Russia is a "comprehensive strategic partner" with China, and the bilateral relation is at the best level in history [25]. Last but not the least, Russia is one of the most important partners in the BRI. These points encouraged CNPC to decide to invest in the Yamal project, as participation could increase the company's influence and add benefits beyond the natural resources.

Just like the preview of CNPC, Sino-Russian cooperation in the Yamal project soon attracted the attention from Chinese government under the BRI. In the subsequent meeting between the Chinese and Russian Premiers, cooperation regarding the Arctic region was mentioned. At the 2017 Belt and Road Forum in Beijing, Russian President Vladimir Putin declared his wish that the Arctic navigation route could be coordinated with the BRI. As if in response to Putin's suggestion, Chinese President Xi Jinping in 2017 mentioned during his visit to Moscow that China and Russia should cooperate on an Arctic navigation route and build up the "Polar Silk Road." It should not be seen as surprising that the concept of the "Polar Silk Road" was formally launched in the White Book of "China's Arctic Policy" in January 2018 [26].

Although Russia and China hold the high political tone in the Arctic region cooperation, both the Russian version of the "North Route" and the Chinese BRI indicate that the economic value of the Arctic region is mostly rooted in transportation and energy cooperation. Currently, the Arctic-based Europe-Asia route is still in its early stage, and the Yamal project has become the single realistic focus for the Northern Sea Route [27]. Under this scenario, as the only large-scale energy cooperation project between two great powers in the strategic Arctic, Yamal naturally has received special political status.

\section{The module-plug-in model in cooperation}

As stated above, CNPC is neither the majority shareholder nor the operator in the Yamal project; therefore, the traditional UDI model is no longer possible to practice, as the Russian company Novatek is operator and the proposed market of the Yamal project is Europe. Then, under the light of the BRI, CNPC timely adjusted its own position from that of operator to that of constructive partner in the relation with Russian companies, and a coordinator in the relation with Chinese domestic companies, introducing Chinese companies into the Yamal project [28]. The effort co-exists the West's sanction against Russia, and CNPC's strategy created many business opportunities for Chinese companies. 
Cooperation in the Yamal project launched the Chinese business presence in Russia oil industry into the historical record, as Chinese companies participate also in every sector in the industrial chain and supply key parts and modules, from upstream exploration and development, to building of modules and ships, to sales and the LNG transportation. Seven of 10 mode builders of the Yamal project are Chinese, some of them belong to CNOCs while others do not, and their workload accounts for $83 \%$ of the whole project. According to CNPC statistics, seven Chinese companies supply 120 of 142 modes, seven of 30 ships, and one in four types of drilling equipment in polar areas for the Yamal project. Meanwhile, Chinese shipbuilders construct 14 out of 15 LNG ships [29].

At the same time, because the ample production capacity of Chinese companies and fierce domestic market competition, the amount bided of Chinese companies are $30 \%$ lower those of than South Korean counterparts, and the Yamal project enabled these Chinese companies survive and develop in the global economic boom and low oil price circle. Participating in the Yamal project provided Chinese companies not only cash flow and profits, but, more importantly, the experience of operating international projects [30]. Because of the performance and experience in the Yamal project, Chinese companies actively participated in Russia's second large-scale LNG project, the Arctic LNG-2, in which CNPC and CNOOC each hold a $10 \%$ share.

In the case of the Yamal project, the role of CNPC has shifted from that of operator to that of international partner and domestic coordinator. Meanwhile, the mobilizationbased UDI model is also substituted by the industrial chain-cooperation model. In this approach, different Chinese companies, according to their own strategy and advantages, can find business opportunities they can handle in the overall industrial chain. Thus, in this kind of oil and gas cooperation, oil and gas are no longer the major ends; instead, natural resources provide a context for international cooperation, and Chinese companies can find commercial profits or international cooperation experience. This approach is also reshaping the CNPC, as its critical focus in the Yamal project is "business" rather than "oil/gas". Although this is business-focus is the mainstream approach for most advanced international oil companies, it is still new for CNPC, which is derived from Chinese Ministry of Petroleum and regards energy supply security as the primary goal.

\section{Multi-actors and market mechanism based cooperation}

As the direct result of the market mechanism under the BRI, the Chinese actors in the Yamal project are diversified. As introduced in last paragraph, different Chinese oil and construction companies participate the in Yamal project. As the follow-up issue to Yamal, both CNPC and CNOOC have shares in Russias new Arctic LNG-2 project. Moreover, beside these oil and construction companies, there are also financial institutions from China investing or providing financial service to the Yamal project. Although it is not news that Chinese financial institutions get involved in international oil and gas cooperation, the Yamal project is noteworthy in that Chinese financial institutions make decisions based on their own investment strategy, not to provide financial assistance to a resource-centered purpose. Based on their observation of the Russian gas policy and market, China and CNPC both appreciate the dynamics and development potential of the emerging Russian energy company Novatek; however, in past, China was more inclined to cooperate with Gazprom, which has more state background and more reserve equipped but also more 
ossified giant [31]. The Sino-Russian oil and gas cooperation scenario of "Zhongnanhai + CNPC vs. Kremlin + Gazprom" has certainly changed. It should be noticed that the Yamal LNG cannot be directly transported to China cross the Sino-Russian border, as the Yamal LNG requires long distance marine transportation as well. From this perspective, China is less inclined to considers the international oil and gas cooperation through a securitization perspective, and CNOCs' strategy, like that of China itself, to realize energy supply security is changing to become more flexible and more market-based.

The Silk Road Fund in December 2015 acquired a 9.9\% share of the Yamal project from Novatek, and additionally provided 15 -year long loans valued at $€ 730$ million to the project [32]. The Silk Road Fund itself was established as a key part of the BRI, aiming at long-term equity investment. Different from CNPC, the Silk Road Fund behaves in the Yamal project as international standard professional financial investor: its attention is entirely focused on the financial performance and potential development of the Yamal project. It is interesting that although it is also a Beijing-based Chinese state-run business, the Silk Road Fund attempted to make the process of decision- making independent and intentionally did not consult with CNPC, as the Silk Road Fund is cautious to the possible misinformation provided by CNPC, the $20 \%$ shareholder of Yamal project. The involvement of the Silk Road Fund raised the overall Chinese share in the Yamal project to $29.9 \%$, higher than the $25 \%$ cap in strategic construction stipulated by Russian government. Apart from CNPC and the Silk Road Fund, the Export-Import Bank of China and the China Development Bank also provide loans valued at $€ 9.3$ billion and CNY 9.8 billion to finance the Yamal project [33]. The financial activities around the Yamal project in China are commercial interests that are not driven by resource access, unlike the previous Sino-Russian energy cooperation, as the energy will be supplied to Europe with priority.

The attitude toward the products of the Yamal project reflects the new transition of Chinese energy supply strategy. In past 2 decades, China was inclined to realize energy supply security through bilateral cooperation. However, after Xi Jinping took power and the BRI was implemented, the energy supply has been increasingly regarded as a market mechanism. As the main shareholder of the Yamal project, CNPC has the right to buy 3 million tons; however, CNPC does not ship all of them back to China. Instead, according to prices of different markets, CNPC selects to sell the partial LNG it obtained in the Yamal project to Europe when the Asian market was not so vigorous whereas the European clients include Vitol, Trafigura, and BP [34]. Of course, Chinese market does not exclude Yamal LNG either, as the first ship of Yamal LNG reached to Jiangsu LNG terminal in June 2018 [35]. In the process, Yamal LNG does not have much special security implication or any special arrangement in the Chinese market, as Yamal LNG has to compete with LNG from Qatar and Australia, pipeline gas from Central Asia and Myanmar, domestically produced gas, and even potentially with the Russian gas from Power of Siberia and American gas from Alaska in the future [36].

\section{Conclusion}

For China under Xi Jinping's leadership, the BRI is the guideline for both diplomacy and economic cooperation. Although CNOCs' international oil and gas cooperation predates the BRI, it has to echo the key requests and leitmotif of the mega economic initiative, and finally merged into it. Because of the fundamental principles and market mechanism 
of the BRI, China's international oil and gas cooperation shows several new transitions. Different from the two-decade-long resource-centered approach, CNOCs have gradually shifted their role in international cooperation from that of the operator in the overseas to international partners and domestic coordinators, in order to diversify equities and risks. The cooperation model changes from upstream-downstream integration to industrial chain-based cooperation, in which specialized competitiveness is emphasized, with a focus on exporting China's industrial capacity like engineering service, construction, and equipment. In business organization, the Chinese actors are no longer sufficiently highly organized to work around the resource-centered investments. Instead, different companies seek their own interests in the whole industrial chain. Under this transition, China's energy security strategy is also re-shaped, as China increasingly adopts the market mechanism to solve the energy security, and becomes more and more prudent toward the securitization approach of energy supply that dominated in China's overseas oil and gas cooperation in past two decades. The Yamal project provides a terse but relevant case to display above points.

\section{References}

1. Xi, J. (2014), Speech on the $6^{\text {th }}$ meeting of Small Leading Group of Finance and Economy, June 13, Beijing, available at: http://www.xinhuanet.com/politics/2014-06/13/c_1111139161.htm (accessed: 21.11.2019). (In Chinese)

2. BP. Statistical Review of World Energy (64 $4^{\text {th }}$ Edition) (2015), available at: https://www.bp.com/content/dam/bp-country/es_es/spain/documents/downloads/PDF/bp-statistical-review-of-world-energy2015-full-report.pdf (accessed: 21.11.2019).

3. CNPC (2016), 2015 Annual Report of CNPC, available at: http://www.cnpc.com.cn/en/xhtml/ pdf/2015_Annual_Report_online/0-2015_Annual_Report.pdf (accessed: 21.11.2019)/

4. Sinopec Group: Annual Report of Sinopec Group of 2015 (2016), available at: http://www.sinopec.com. hk/WebRoot/userdocuments/D143021AD48ACCCEC4CA2D98664B2AF3/enfile/Att/87968225.pdf (accessed: 21.11.2019).

5. Xi, J. (2013), Speech at Nazarbayev University, September 8, Astana, available at: http://www.xinhuanet.com/politics/2013-09/08/c_117273079_2.htm (accessed: 21.11.2019). (In Chinese)

6. Xi, J. (2016) Speech at the B20 Summit (Meeting for Business in G20), September 3, Hangzhou, available at: http://www.xinhuanet.com//world/2016-09/03/c_129268346.htm (accessed: 21.11.2019). (In Chinese)

7. Xi, J. (2018), Speech at the Boao Asia Forum, Boao, April 10, available at: http://www.xinhuanet.com// politics/2018-04/10/c_1122659873.htm (accessed: 21.11.2019). (In Chinese)

8. Wang, X. (2019), Does Structural Power of Business Matter?: Evidence from China’s Oil Politics under Xi Jinping, Pacific Focus, vol. 34 (2), pp. 284-312.

9. NDRC: Vision and Actions on Jointly Building Silk Road Economic Belt and $21^{\text {st }}$-Century Maritime Silk Road (2015), available at: http://en.ndrc.gov.cn/newsrelease/201503/t20150330_669367.html (accessed: 21.11.2019).

10. Yang, Y. et al. (2015), Study on Energy Cooperation between China and the Central Asia and Russia under the View of Energy Geopolitics, Geographic Research, vol. 34(2), pp. 213-224.

11. Corkin, L. Uneasy Allies: China's Evolving Relations with Angola, Journal of Contemporary African Studies, vol. 29, pp. 169-180.

12. Kenderdine, T. and Ling, H. International Capacity Cooperation-Financing China's Export of Industrial Overcapacity, Global Policy, vol. 9 (1), pp. 41-51.

13. Lu, R. (2019), BRI, Chinese Oil and Gas Industry and the World, Petroleum Industry Press. (In Chinese)

14. Wang, X. and Wang, Z. (2019), Is China Able to Export Its Developmental Model? The Upstreamdownstream Integration Model in Sino-African Petroleum Engagement, Transnational Corporations Review, available at: https://doi.org/10.1080/19186444.2019.1687223 (accessed: 21.11.2019).

15. Cui, M. and Liu, G. (2017), Learning from Yamal LNG Project, China Petroleum Daily, November 29. (In Chinese) 
16. Lu, R. et al. (2015), The version 2.0 of oil and gas cooperation in BRI, International Petroleum Economics, vol. 23 (11), pp. 15-18. (In Chinese)

17. Meidan, M. (2017), China's Independent Refiners: A New Force Shaping Global Oil Market, Energy Insight of the Oxford Institute for Energy Studies, no. 2, available at: https://www.oxfordenergy.org/wpcms/ wp-content/uploads/2017/05/Chinas-Independent-Refiners-A-New-Force-Shaping-Global-Oil-MarketsOIES-Energy-Insight.pdf (accessed: 21.11.2019).

18. Luo, G. et al. (2019) China Moves to Create National Pipeline Titan, Caixin Global, March 20, available at: https://www.caixinglobal.com/2019-03-20/china-moves-to-create-national-pipeline-titan-101394799. html (accessed: 21.11.2019).

19. Yamal LNG, available at: http://yamallng.ru/en/ (accessed: 21.11.2019).

20. Tillman, H. et al. (2018), The Polar Silk Road: China's New Frontier of International Cooperation, China Quarterly of International Strategic Studies, vol. 4 (3), pp. 345-362.

21. Xu, T. et al. (2019), Yamal Project is Completed in Advance, Oil and Gas Cooperation speeds up within the BRI, International Petroleum Economics, no. 1, pp. 25-26. (In Chinese)

22. Lunden, L. et al. (2013), Gazprom vs. Other Russian Gas Producers: The Evolution of the Russian Gas Sector, Energy Policy, no. 61, pp. 663-670.

23. Henderson, J. and Moe, A. (2017), Russia's Gas 'Triopoly': Implication of a Changing Gas Sector Structure, Eurasian Geography and Economics, vol. 58 (4), pp. 442-468.

24. Henderson, J. and Moe, A. (2016), Gazprom's LGN Offensive: A Demonstration of Monopoly Strength or Impetus for Russian Gas Sector Reform, Post-Communist Economies, vol. 28 (3), pp. 281-299.

25. Zhong, S. (2019), China, Russia to take comprehensive strategic partnership of coordination to new level, People’s Daily, May 31, available at: http://en.people.cn/n3/2019/0531/c90000-9583262.html (accessed: 21.11.2019).

26. The State Council Information Office of China (2018), China's Arctic Policy, available at: http://www. scio.gov.cn/ztk/dtzt/37868/37869/37871/Document/1618250/1618250.htm (accessed: 21.11.2019).

27. Moe, A. (2014), The Northern Sea Route: Smooth Sailing Ahead? Strategic Analysis, vol. 38 (6), pp. 784-802.

28. Yang, H. (2019), Interview with Liu Guizhou, China Investment, no. 9, pp. 34-36. (In Chinese)

29. CNODC. News Press about Yamal Project (2019), available at: http://cnodc.cnpc.com.cn/cnodc/gsxw 1/201903/0c43289a121b4e2c982ac774d633f2df.shtml (accessed: 21.11.2019). (In Chinese)

30. Fan, R. and Huang, K. (2019), The Arctic Giant of LNG is Ready to Go, Caixin Weekly, no. 3, pp. 6065. (In Chinese)

31. Özdemir, V., Karbuz, S. (2015), A New Era in Russian Gas Market: The Diminishing Role of Gazprom, Energy Strategy Review, no. 8, pp. 39-44.

32. Silk Road Fund. Silk Road Fund and Novatek Sign Binding Definitive Agreement Regarding Yamal LNG, available at: http://www.silkroadfund.com.cn/enweb/23809/23812/31799/index.html (accessed: 21.11.2019).

33. Yamal LNG (2016), Yamal LNG Signed Loan Agreements with the Export-Import Bank of China and the China Development Bank, April 29, available at: http://yamallng.ru/en/press/news/7540/?pdf=Y (accessed: 21.11.2019).

34. Reuters (2019), PetroChina Boosts European LNG Activity with Yamal Cargos, January 16, available at: https://www.reuters.com/article/us-lng-europe-china-idUSKCN1PA1WT (accessed: 21.11.2019).

35. CNPC (2018), The First Ship of Yamal LNG Arrives at Rudong of Jiangsu, July 24, available at: http:// news.cnpc.com.cn/system/2018/07/24/001698922.shtml (accessed: 21.11.2019). (In Chinese)

36. Paik, K. (2017), Interview with Sputnik, November 12, available at: http://sputniknews.cn/china/201711121024027683/ (accessed: 21.11.2019).

Received: November 21, 2019

Accepted: December 16, 2019

Authors' information:

Qian Liu — PhD, Assistant Professor; liuqian@cup.edu.cn

Xiaoguang Wang — PhD, Assistant Professor; wangxg@cup.edu.cn 